\title{
Spermatozoal competition in common carp (Cyprinus carpio): what is the primary determinant of competition success?
}

\author{
O Linhart, M Rodina, D Gela, M Kocour and M Vandeputte ${ }^{1}$
}

Joint Laboratory of Genetics, Physiology and Reproduction of Fish, University of South Bohemia, Research Institute of Fish Culture and Hydrobiology, 38925 Vodnany, Czech Republic and ${ }^{1}$ INRA Laboratoire de Génétique des Poissons, 78352 Jouy-en-Josas Cedex, France

Correspondence should be addressed to O Linhart; Email: linhart@vurh.jcu.cz

\begin{abstract}
The percentage of sperm motility $(92-100 \%)$, spermatozoan velocity $\left(112-163 \mu \mathrm{m} \cdot \mathrm{s}^{-1}\right)$ and control hatching rates $(83-96 \%)$ were evaluated for each of six gold and five green male common carp (Cyprinus carpio). In all 30 possible paired combinations of sperm-competition tests, hatching rates of 90-97\% were achieved. The mean percentage of offspring sired was strongly influenced by the male used $\left(P<0.001, R^{2}=0.91\right)$. The best male sired an average of $88 \%$ of the offspring in its competition tests, and the worst male sired only $5 \%$. Spermatozoan-quality parameters could explain only part of the variation in male competitive ability. The male effects alone explained $91.4 \%$ of the observed variance, consisting of $17.1 \%$ explained by spermatozoan motility and $32.5 \%$ by control hatching rates in single fertilizations. Undetermined male effects explained $41.8 \%$. The velocity of spermatozoa had no effect on the outcome of sperm competition. Neither was there any link between spermatozoan velocity and hatching rate in a control hatching test, whereas there was an effect of motility on hatching rate in this same test.

Reproduction (2005) 130 705-711
\end{abstract}

\section{Introduction}

Sperm competition occurs when the spermatozoa of several males compete for fertilization. Competition is a major force for spermatozoan selection, but its implications for mating systems and on life-history evolution are only just beginning to be understood (Parker 1998, Gage et al. 2004). Trade-offs between gamete characteristics and relative gametic investment has been modelled by evolutionary stable strategy (ESS) approaches, when the optimal strategy for a male depends on the strategy adopted by other individuals in the population (Ball \& Parker 1996, Parker et al. 1996, Parker 1998, Petersen \& Warner 1998). All of the models assume that males obtain more fertilization success by releasing more sperm, this being done at a cost to investment in other fitness-enhancing functions such as growth, finding additional males, investment in female function, mate defence, territoriality or releasing more sperm in other spawnings. As applied to fish, sperm-competition trials with paternity analysis have been conducted in several salmonid species (Gage et al. 1995, 2002, 2004, Gile \& Ferguson 1995, Liley et al. 2002) and recently also in cyprinids (Kortet et al. 2004, Reichard et al. 2004a, $2004 b$ ) or other species such as bluegill sunfish (Lepomis macrochirus; Burness et al. 2004). In rainbow trout
(Oncorhynchus mykiss) male potency, defined as the ability of males to sire progeny when their sperm is pooled with that of other males, was not affected by the female gametes used, and decreased significantly when sperm concentrations were equalized (Gile \& Ferguson 1995).

Sperm vary in morphology, behaviour (speed, trajectory, percentage of sperm motility, etc.) and longevity in fishes. Currently, the mechanism of this variation is poorly explained (Cosson et al. 1999). There appear to be intraspecific differences that may correlate with male-mating type in Atlantic salmon (Salmo salar; Gage et al. 1995). Fishes show one of the widest ranges of sperm-competition intensity of any animal group (Petersen \& Warner 1998). A comparative study of fishes with external fertilization found that both the gonadosomatic index $\left(l_{\mathrm{G}}\right)$ and sperm numbers increase with intensity of sperm competition across species, but that sperm length decreases (Stockley et al. 1997). Specific models for continuous fertilization suggest that if length increases a sperm's speed but decreases its longevity, sperm length should increase with sperm-competition intensity, whereas models for instant fertilization suggest that sperm length should remain constant. The negative relationship found between sperm competition and sperm length was not predicted (Stockley et al. 1997). The competitive fitness effects of 
Atlantic salmon sperm during in vitro fertilization were studied recently (Gage et al. 2002, 2004). Microsatellite DNA fingerprinting revealed that a male's relative sperm velocity was the primary determinant of sperm-competition success, whereas there was no significant relationship between fertilization success and either relative sperm number or total length of sperm. Sperm longevity showed an inverse relationship with competition success. Atlantic salmon sperm were considered to enter a competition analogous to a race in which the fastest sperm had the highest probability of success (Gage et al. 2002, 2004). Positive association between spermatocrit and energy charge was also detected in Atlantic salmon. Sperm-length parameters correlated positively with ATP, energy charge and fertilization success, whereas no evidence for an effect of sperm morphology on longevity was found. Long sperm tail and midpiece may be selected to optimize energetic demands under conditions of increased sperm competition intensity (Vladic \& Jarvi 2001, Vladic et al. 2002).

Studying competition, different models are proposed according to the reproductive strategies of various species. However, most models are not well-enough designed to simply explain sperm competition during in vitro fertilization, because they involve other variables that are irrelevant in this simple case (trade-offs between physiological and/or behavioural fitness-related traits, for example).

For this study of sperm competition in common carp (Cyprinus carpio), we used typical in vitro fertilization conditions that closely shared many fundamental characteristics of natural fertilization (Linhart et al. 2003). The objective of this study was to find out the extent of competition between sperm from two male carp, identified by green and gold genetic markers, in a factorial crossing design testing all possible sperm combinations of six gold males and five wild-green males. We used experimentally regulated identical numbers of spermatozoa in all doses, with sperms chosen to be highly motile.

\section{Materials and Methods \\ Colour markers for offspring identification}

The offspring in each competition test were identified by wild-green (dominant) and gold (recessive) genetic markers (Katasonov 1973, 1978) in a factorial design testing all possible combinations (30) of five wild-green males (nos 7-11) and six gold Japanese fancy (Koi) males (nos 1-6), all crossed with a single gold female. For each paired competition test, one wild-green male and one gold male were used. The percentages of gold and green offspring gave the result of the competition test, according to Mendelian inheritance (Mendel 1865): wild-green males gave 100\% green offspring and gold males gave $100 \%$ gold offspring. There was no evidence of codominance in crosses involving various colour varieties (Kirpichnikov 1979).

\section{Broodstock handling and collection of gametes}

The reproduction and culture of common carp was carried out at the Department of Fish Genetics and Breeding, RIFCH, University of South Bohemia at Vodnany in the Czech Republic in 2004. Experiments with fish were performed in accordance with UK legal requirements. 4-yearold wild-green males, 7-year-old gold Koi males and 7-year-old female broodstock were maintained in separate ponds until used in the experiments. Broodfish suitable for stripping were selected in May and stocked separately in the hatchery in $4 \mathrm{~m}^{3}$ tanks with a water flow rate of $0.2 \mathrm{I} \cdot \mathrm{s}^{-1}$, temperature of $18-22^{\circ} \mathrm{C}$ and $6-7 \mathrm{mg} \cdot \mathrm{I}^{-1} \mathrm{O}_{2}$.

For the experiment, all fish were first anaesthetized in a solution of 2-phenoxyethanol (1:1000). 16 males (eight green and eight gold) were injected with carp pituitary at $1 \mathrm{mg} \cdot \mathrm{kg}^{-1}, 24 \mathrm{~h}$ before stripping at $21^{\circ} \mathrm{C}$. Sperm was collected individually from each male and kept in a thin layer in cell-culture vessels under aerobic conditions at $0^{\circ} \mathrm{C}$. Prior to fertilization, the motility of sperm was checked by microscopy and only 11 males (six gold and five green) with sperm motility of better than $90 \%$ were used for the sperm-competition experiment.

Two gold females were used for the experiment and injected with carp pituitary at 0.4 and then $2.1 \mathrm{mg} \cdot \mathrm{kg}^{-1}, 24$ and $12 \mathrm{~h}$ before stripping, respectively (Linhart et al. 2003). The females were stripped into separate dishes. Ova were stored under aerobic conditions at $17-19^{\circ} \mathrm{C}$ for $2-4 \mathrm{~h}$ prior to artificial insemination (Rothbard et al. 1996). For the experiment, only the female exhibiting ova without whitish colour (which mostly occurs in over-mature ova) and without pollution (i.e. by urine or excrement) was used.

Prior to the fertilization experiments with different males, the initial sperm concentration of all 11 males was estimated using a Burker cell haemocytometer (16 squares counted for each sperm of each male) under Olympus microscope BX $41(400 \times)$ and expressed in billions per $\mathrm{ml}$ (Table 1). From this concentration the volume of sperm from each male was calculated as containing $4 \times 10^{8}$ spermatozoa, so that there would be 100000 spermatozoa from each male per egg in the competition tests. Three batches of approximately $0.3 \mathrm{~g}$ (around 200 eggs) of unfertilized eggs were weighed to the nearest $0.0001 \mathrm{~g}$, and then fixed in $4 \%$ formaldehyde for later counting and determination of non-fixed mean egg weight. The number of eggs was then calculated in each experiment from the weight of eggs and expressed as number per g eggs.

\section{Competition of two males during in vitro fertilization}

Eggs ( 5 g; 800 eggs per g) were placed into a $50 \mathrm{ml}$ dish and sperm from one green and one gold male were simultaneously added in volumes corresponding to $40 \times 10^{7}$ spermatozoa per male. The dish was then placed on an orbital agitator (200 r.p.m., $10 \mathrm{~mm}$ deflection). Water $(5 \mathrm{ml})$ was added for activation. 2 min later, 300-600 fertilized eggs were placed with three replicates into special incubation cages of $200 \mathrm{ml}$ supplied with UV-sterilized 
Table 1 Mean characteristics of the 11 male common carp in sperm-competition tests, including covariates describing sperm quality: sperm motility (\%), spermatozoan velocity, initial sperm concentration and hatched larvae (\%) in a control fertilization test.

\begin{tabular}{|c|c|c|c|c|c|c|c|}
\hline Sire & $\begin{array}{l}\text { Genetic } \\
\text { marker }\end{array}$ & $\begin{array}{l}\text { Male weight } \\
(\mathrm{kg})\end{array}$ & $\begin{array}{l}\text { \% Sired larvae in } \\
\text { competition }\end{array}$ & $\begin{array}{l}\text { Motility } \\
(\%)\end{array}$ & Velocity $\left(\mu \mathrm{m} \cdot \mathrm{s}^{-1}\right)$ & $\begin{array}{l}\text { Initial concentration } \\
\quad\left(\mathrm{spz} / \mathrm{ml} \times 10^{9}\right)\end{array}$ & $\begin{array}{l}\% \text { Hatched larvae } \\
\text { in control }\end{array}$ \\
\hline 1 & Go & 3.1 & 66.0 & 98.9 & 127 & 25.5 & 91.4 \\
\hline 2 & Go & 2.7 & 5.5 & 96.6 & 148 & 22.3 & 83.4 \\
\hline 3 & Go & 2.1 & 42.5 & 99.1 & 138 & 29.8 & 90.2 \\
\hline 4 & Go & 1.8 & 69.6 & 100.0 & 163 & 26.7 & 94.7 \\
\hline 5 & Go & 2.1 & 74.1 & 99.7 & 151 & 21.7 & 96.0 \\
\hline 6 & Go & 1.7 & 86.3 & 100.0 & 140 & 25.3 & 86.8 \\
\hline 7 & Gr & 1.1 & 27.6 & 100.0 & 145 & 30.0 & 86.1 \\
\hline 8 & Gr & 1.3 & 40.9 & 94.1 & 111 & 26.6 & 90.8 \\
\hline 9 & Gr & 1.0 & 55.8 & 98.5 & 129 & 20.2 & 92.2 \\
\hline 10 & Gr & 1.0 & 34.9 & 93.0 & 149 & 22.8 & 93.3 \\
\hline 11 & Gr & 1.3 & 28.2 & 94.9 & 125 & 19.8 & 89.0 \\
\hline
\end{tabular}

Go, gold; Gr, green; spz, spermatozoa.

recirculated dechlorinated tap water at $22^{\circ} \mathrm{C}$ and $\left.9 \mathrm{mg} \cdot\right|^{-1}$ $\mathrm{O}_{2}$. For each male, a sperm fertilization and hatching control test was also performed, using the appropriate volume to fertilize $5 \mathrm{~g}$ eggs with $8 \times 10^{8}$ spermatozoa.

\section{Calculation of fertilization and hatching}

The eggs were counted in each cage and during incubation dead eggs were counted and removed, and then hatched fry (green and gold) were counted, usually up to 4.5 days of incubation at $22^{\circ} \mathrm{C}$. The fertilization rate was calculated as the ratio of live eggs at $24 \mathrm{~h}$ post-fertilization to the initial number of eggs per cage.

The hatching rate was calculated as the ratio of hatched larvae (green and gold, $H_{1}$ ) to the initial number of eggs per cage. The total number of offspring scored was 12239 with 282-501 per individual cross.

\section{Observation of sperm motility and velocity}

Directly after in vitro fertilization, sperms were videorecorded for exact evaluation of the percentage of motility and velocity from three individual records per male. Darkfield microscopy and a Sony camera were used for measurements as described by Linhart et al. (2002). Percentage of motility and velocity were examined under $20 \times$ objective magnification immediately after mixing $1 \mu \mathrm{l}$ (prediluted sperm with immobilizing solution, 1:200; Linhart et al. 2002) sperm with $49 \mu$ l distilled water $+0.1 \%$ $\mathrm{BSA}$, on a glass slide positioned previously on the microscope stage. The final dilution was 1:10000. The BSA was added only to prevent sperm heads from sticking to the glass slide. Within $10 \mathrm{~s}$ of mixing, a video recording was made for $2 \mathrm{~min}$ to be used in the evaluation of spermatozoan swimming activity. The focal plane was always positioned near the glass slide's surface. The movements of spermatozoa were recorded using a S-VHS (Sony; SVO$9500 \mathrm{MDP}$ ) video recorder at 50 half frames $\cdot \mathrm{s}^{-1}$ using a CCD video camera (Sony; SSC-DC50AP) mounted on a dark-field microscope (Olympus BX 50) and visualized on a video monitor illuminated with a stroboscopic lamp of
Strobex (model no. 9630; Chadvick-Helmut, USA). The adjustable frequency stroboscopic flash illumination was set in automatic register with video frames $(50 \mathrm{~Hz})$ for sperm velocity measurement.

\section{Evaluation of the velocity and percentage of motility}

Velocity and motility were assessed at $15 \mathrm{~s}$ after activation: the successive positions of the video-recorded sperm heads were analysed from video frames by means of Olympus Microlmage software (version 4.0.1. for Windows with a special macro by Olympus $C \& S$ ). The velocity and percentage of motility were measured by evaluating spermatozoan head positions on five successive frames with three different colours (frame 1, red; frames 2-4, green; frame 5, blue). 20-40 spermatozoa were evaluated from each frame. Spermatozoa that moved were visible in three colours, while non-moving spermatozoa were white. The percentage of motile spermatozoa was easily calculated from white versus red cells. The velocity of spermatozoa was calculated as $\mu \mathrm{m} \cdot \mathrm{s}^{-1}$ based on length traces of spermatozoa from blue to green and red heads, calibrated for magnification.

\section{Statistical analysis}

Prior to analysis, all percentages (variables and covariates) were arcsine-transformed $\left(Y_{2}=\operatorname{arcsine}\left(\sqrt{ } Y_{1}\right)\right)$ for variance stabilization. To evaluate the effect of sires on competition results, the percentages of green larvae in each competition cross (one green male against one gold male) were analysed with a two-way analysis of variance (ANOVA), with gold male ID and wild-green male ID as independent factors. The analysis was performed on the percentage of green larvae, but as the sum of green and gold larvae was $100 \%$, it gave equivalent information on the percentage of gold larvae (for example, a gold male having a negative effect on the percentage of green larvae also has a positive effect on the percentage of gold larvae). Differences between means of males were assessed with Tukey's 
studentized range test. Normality of residuals was assessed with the Shapiro-Wilk test.

Analysis of covariance (ANCOVA) was conducted on the mean (arcsine-transformed) proportion of offspring sired by each male in all the crosses where it had been used, to assess the impact of male origin (gold or green strain) and covariates on the mean competitive value of a male. The covariates tested were sperm-quality indices: arcsine-transformed percentage motility, arcsine-transformed percentage hatching in sperm control tests, spermatozoan velocity and initial sperm concentration (number of spermatozoa per $\mathrm{ml}$ ). The weight of males at the time of stripping was also used as a covariate. Covariates were tested for homogeneity of slopes among gold and green males. All analyses were performed with SAS-GIm.

\section{Results}

Fertilization and hatching were not significantly different; therefore, only hatching results are presented. Hatching results in the control experiments show the good quality of the sperm and egg samples used for the competition experiment (Table 1). Percentage of sperm motility (93-100\%), spermatozoan velocity $\left(111-163 \mu \mathrm{m} \cdot \mathrm{s}^{-1}\right)$ and control hatching rates $(83-96 \%)$ were evaluated for each gold and green male. In paired competition tests, hatching rates of $90-97 \%$ were achieved. The mean percentages of offspring sired, given for each male (green offspring for green males and gold offspring for gold males) were significantly the best for gold male nos 1, 4, 5 and 6 , with $67-89 \%$ gold offspring, and for green male no. 9 with $56 \%$ green offspring. By contrast, gold male no. 2 sired only $5 \%$ of the offspring on average (Table 2). Both gold and green males had a highly significant effect on the proportion of green offspring $(P<0.001)$, and their crossed effects explained more than $91 \%$ of the observed variance, showing that male effects on sperm competitive ability are both strong and essentially additive (although interaction could not be tested, most of the variance is explained by the main effects). In the ANCOVA analysis, there was an effect of male type (green or gold) on the percentage of offspring sired $(P<0.05)$. The total percentage ratio of gold:green offspring was 58:42.

Regression slopes were homogeneous among types of males for the covariates percentage hatching in sperm control tests $(P>0.8)$, initial sperm concentration $(P>0.4)$, spermatozoan velocity $(P>0.8)$ and weight of males at the time of stripping $(P>0.6)$. When percentage motility was used as a covariate, the regression slopes were heterogeneous $(P<0.05)$, with a strong positive association between percentage motility and percentage of offspring sired in gold males (slope $a=4.24, P<0.05$ ) and no association $\left(a^{\prime}=-0.08, P>0.9\right)$ in green males (Fig. 1). However, the difference between the two colour strains came mainly from one green male (male 7), which had $100 \%$ motility but only $27 \%$ of the offspring sired. Without this male, the slopes would have been homogeneous $(P>0.1)$, with a positive association between the percentage of offspring sired and percentage motility $\left(R^{2}=0.57, a=2.13, P<0.02\right)$.

Regression of the percentage of offspring sired on the percentage of hatching in sperm control tests was relatively close to significance, with a positive (although not significant) association $(a=1.89, P=0.09)$. When weight of males at the time of stripping was used as a covariate, the regression was again close to significance $(P=0.10)$, this time with a negative association with percentage of offspring sired $(a=-0.28)$. There was no significant regression on percentage of offspring sired when initial sperm concentration $(P>0.6)$ or spermatozoan velocity $(P>0.9)$ were used as covariates.

When differences between motilities and hatching rates were introduced as covariates in the initial two-way ANOVA, they were both significant $(P<0.01)$, but the effects of green and gold males also remained significant $(P<0.0001)$, showing that these sperm quality parameters explain only part of the variation in males competitive ability. In the initial analysis, the percentage of variance explained by the effects of males was $R^{2}=91.4 \%$. When the covariates were added, difference in sperm motilities explained $17.1 \%$ of the variance, difference in control

Table 2 Sperm competition between two male common carp identified by green (Gr) and gold (Go) genetic markers, in a factorial crossing design testing all possible combinations of six gold males (nos 1-6) and five green males (nos 7-11). For each cell, percentages of gold:green offspring are given. Mean percentages of offspring sired are given for each male (offspring for green males, and offspring for gold males). Means with different superscripts are significantly different (Tukey's test. $P<0.05)$. The total number of offspring scored was $12.239(282-501$ per individual cross). Hatching rates were $90 \%$ or higher for each cross.

\begin{tabular}{|c|c|c|c|c|c|c|c|}
\hline \multirow[t]{2}{*}{ Gold male } & \multicolumn{6}{|c|}{ Gold:green offspring (\%) } & \multirow[b]{2}{*}{ Mean $\%$ of gold offspring } \\
\hline & Green male... & 7 & 8 & 9 & 10 & 11 & \\
\hline 1 & & $70.6: 29.4$ & $62.1: 37.9$ & $24.1: 75.9$ & $87.7: 12.3$ & $85.4: 14.6$ & $66.0^{\mathrm{ab}}$ \\
\hline 2 & & 10.4:89.6 & 6.4:93.6 & 1.2:98.8 & 2.8:97.2 & $6.5: 93.5$ & $5.5^{\mathrm{c}}$ \\
\hline 3 & & $68.4: 31.6$ & $35.8: 64.2$ & 7.9:92.1 & $37.2: 62.8$ & $63.0: 37.0$ & $42.5^{\mathrm{b}}$ \\
\hline 4 & & $82.8: 17.2$ & $77.8: 22.2$ & $32.8: 67.2$ & $65.0: 35.0$ & $89.8: 10.2$ & $69.6^{\mathrm{a}}$ \\
\hline 5 & & 83.8:16.2 & $92.8: 7.2$ & $55.1: 44.9$ & $52.4: 47.6$ & $86.2: 13.8$ & $74.1^{\mathrm{a}}$ \\
\hline 6 & & $97.4: 2.6$ & $78.5: 21.5$ & $65.6: 34.4$ & $94.5: 5.5$ & $95.6: 4.4$ & $86.3^{\mathrm{a}}$ \\
\hline Mean $\%$ of green offspring & & $27.6^{\mathrm{b}}$ & $40.9^{\mathrm{b}}$ & $55.8^{\mathrm{a}}$ & $34.9^{\mathrm{b}}$ & $28.2^{\mathrm{b}}$ & \\
\hline
\end{tabular}




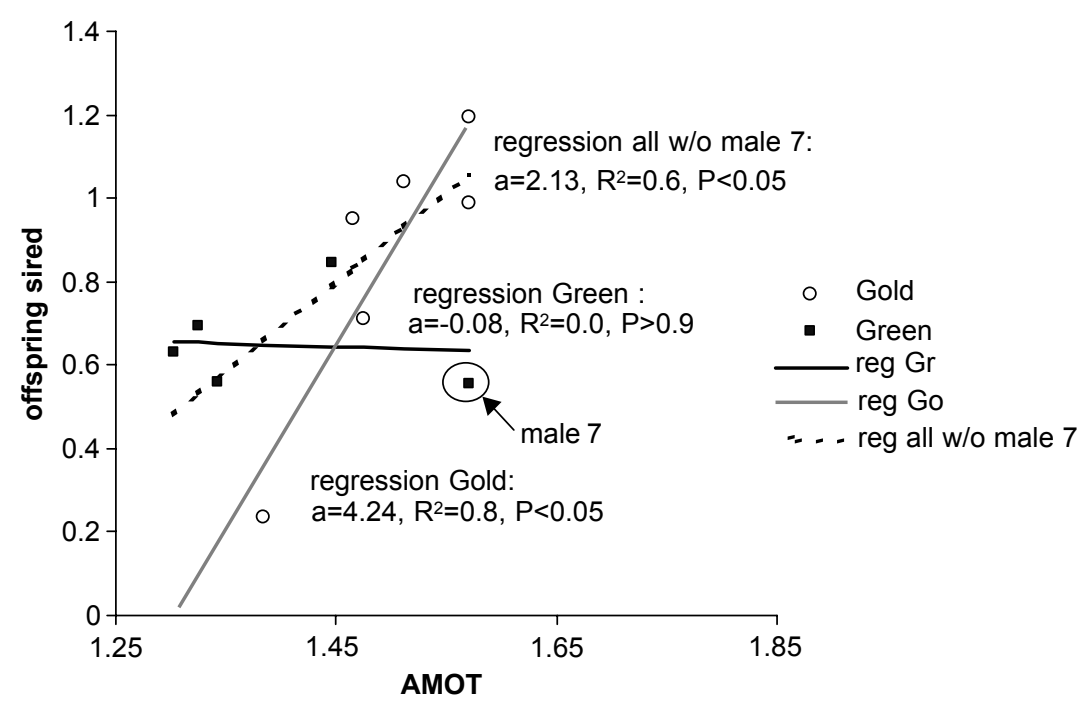

Figure 1 Mean arcsine-transformed proportion of offspring sired in sperm competition conditions by 11 gold (Go) or green (Gr) male common carp, compared with arcsine-transformed sperm motility (AMOT). Partial regressions for gold and green males, as well as for all males except male 7 , are plotted; $a=$ slope of the regression. hatching rates explained $32.5 \%$ and the combined male effects explained $41.8 \%$ of the variance.

\section{Discussion}

Oviparous fish species such as common carp have a reproduction strategy in which a very short period of sperm reaction is needed to achieve their goal. The sperm exhibit a hypermotile behaviour remarkably similar to the so-called hypermotility of mammalian sperm in the vicinity of eggs before fertilization (Cosson et al. 1999). The hypermotility of fish sperm is fully triggered when released in a new ionic/osmotic environment and is expressed by an initial high beat frequency, high velocity and consequently fast energy consumption. It is possible that such behaviour is dictated by an evolutionary constraint, that is, the short period in which an egg can be fertilized due to the limited time (a few seconds in many fish species) of micropyle permeability (Cosson et al. 1999).

Here, when compared with other competitive experiments with external fertilization in fish, the attempt was made to use not only the same quantity of sperm from rival males, but also sperm with similar, good motility. When the effect of sperm number is suppressed, then, according to published results in fishes with external in vitro fertilization, fertilization success reflects sperm motility (Lahnsteiner et al. 1998) and velocity of spermatozoa (Gage et al. 2002, 2004). Surprisingly, the variation of sired offspring was very high with gold:green ratios ranging from 1:99 to 98:2, but these proportions were not significantly influenced by the large variation in velocity (from 112 to $163 \mu \mathrm{m} \cdot \mathrm{s}^{-1}$ ) of competitive spermatozoa. However, published results do not always show a positive effect of velocity; for example, the highest sperm velocities were associated with a reduction of fertilization rate in rainbow trout (Lahnsteiner et al. 1998).

The application of an adequate sperm:egg ratio for high fertilization/hatching rate was an important parameter in the experimental design. In classical fertilization studies, optimal sperm:egg ratio is used for discrimination of fertilization effect (Billard \& Cosson 1992), when the fertilization/hatching success is used as a potential predictor of sperm quality. In the present study, the control hatching rates ranged from 83 to $96 \%$ (Table 1), motility was more than $93 \%$ (with variation from 93 to $100 \%$ ) and velocity was higher than $111 \mu \mathrm{m} \cdot \mathrm{s}^{-1}$ (with variation from 111 to $163 \mu \mathrm{m} \cdot \mathrm{s}^{-1}$ ), proving the very good quality of sperm from individual males. Sperm with high motilities and velocities were selected to avoid or minimalize evident effects on the competitive ability of males (e.g. non-motile versus highly motile sperm would evidently give a positive linkage between motility and competitive ability). Numbers of fresh spermatozoa ranging from 9000 to 30000 per egg are required for minimal in vitro fertilization in common carp, but the practical quantity of sperm recommended for artificial propagation is 100 000-200000 (Billard et al. 1995, Linhart et al. 2003). 200000 spermatozoa per egg were used in the present experiments. The rates of sperm and egg dilution with activating medium (water, activation solution, etc.) during the process of fertilization are other parameters that must be well adjusted. A sperm-dilution ratio of 1:25 (sperm:water) and an egg-dilution ratio of 1:1 were used. Both rates were suitable for artificial propagation of common carp in previous studies (Linhart et al. 2003). Present results show that some carp males reproductively win a greater proportion of the paternity in a competitive situation. In the Atlantic salmon, sea urchins and fowl, the same is observed, and in these cases the sperm milt containing the faster spermatozoa are the most efficient (Birkhead et al. 1999, Levitan 2000, Gage et al. 2004). These results in Atlantic salmon and sea urchins are logical, because increased velocity will enable sperm to search the spawning microenvironment at a faster rate per time unit, and to penetrate earlier than rival sperm (Gage et al. 2004). Interestingly, in Atlantic salmon, sperm 
number is not the primary determinant of sperm competition success (Gage et al. 2004), in contradiction with the theory of competition (Parker 1982) and comparative (Stockley et al. 1997) and experimental (Martin et al. 1974) findings in other species (Gage et al. 2004). In the present results, there were no links between sperm velocity and percentage of offspring sired in competition or between sperm velocity and percentage of hatching in the sperm control test $\left(N=11, R^{2}=0.03, P>0.6\right.$; Table 1$)$. On the other hand, there was an effect of motility on hatching in the sperm control test $\left(N=11, R^{2}=0.38\right.$, $P<0.05$; Table 1), and a strong association between sperm motility and percentage of offspring sired in gold males but not in green males. When one green male (male no. 7), with a low level of sired offspring (27.6\%; Table 1), was excluded, then there was a global association, for all males, between motility and percentage of offspring sired in competition.

Finally, sperm motility seems to explain part of the strong male effect on competitive ability, although all males used here had different but excellent motilities (from 93 to 100\%). Percentage sperm motility has been recognized as an important spermatozoal trait for male fertility in rainbow trout (Moccia \& Munkittrick 1987, Ciereszko \& Dabrowski 1994, Lahnsteiner et al. 1998), human (Donnelly et al. 1998) and poultry (Donoghue 1999). The present study indicates that $91 \%$ of the variance in sperm competition of common carp with different percentages of sired larvae in competition can be explained by differences between the sperm of the competent males (different sperm motility, different hatching, different colour, etc). When different parameters of sperm were analysed, then $17.1 \%$ of the variance in larvae sired in competition can be explained by differences in sperm motilities and $33 \%$ can be explained by differences in control hatching rates. But still $42 \%$ of that variance cannot be explained. Unfortunately when a large quantity of sperm was used for evaluation of sired larvae in competition, differences of spermatozoan velocity were not significant with larvae sired in competition. Given only this information, there was no link between velocity of sperm and percentage of larvae sired in competition.

The $32 \%$ variation in velocity of spermatozoa was very high, from 111 to $163 \mu \mathrm{m} \cdot \mathrm{s}^{-1}$. It could be that such variation of $32 \%$ was not important or discriminative for such a quantity of sperm (200000 spermatozoa per egg) and that such a quantity of sperm oversaturated and masked any effect of a difference in velocity. So, it can be concluded that differences due to variation in the velocity of spermatozoa can be masked by the quantity of sperm, but the effects of sperm motility are masked less by the quantity of sperm. But still there is no explanation for $42 \%$ of the variance of larvae sired in competition. Such phenomena can be explained by male-male competition but, as Birkhead and Møller (1998) have pointed out, such simple mechanisms potentially belie much more complex malefemale interactions. Such phenomena can also be explained by mechanisms which result in the differential utilization of sperm, depending on the recognition of gametes according to their immunological competition (Wedekind et al. 1995, Zeh \& Zeh 1997).

\section{Acknowledgement}

Funding is acknowledged from USB RIFCH no. MSM6007665809, GACR no. 524/03/0178, GACAS no. S5045314GACR and BARRANDE no. 44/2004. We thank Mrs Benjamine Vandeputte for advice on statistical evaluation. The authors declare that there is no conflict of interest that would prejudice the impartiality of this scientific work.

\section{References}

Ball MA \& Parker GA 1996 Sperm competition games: External fertilization and "adaptive" infertility. Journal of Theoretical Biology $180141-150$.

Billard R \& Cosson MP 1992 Some problems related to the assessment of sperm motility in fresh water fish. Journal of Experimental Zoology 261 122-131.

Billard R, Cosson J, Perchec G \& Linhart O 1995 Biology of sperm and artificial reproduction in carp. Aquaculture 129 95-112.

Birkhead TR \& Møller AP 1998 In Sperm Competition, Sexual Selection and Different Routek to Fitness. Sperm Competition and Sexual Selection, pp 757-781. Eds TR Birkhead \& AP Møller. London: Academic Press.

Birkhead TR, Martinez JG, Burke T \& Froman DP 1999 Sperm mobility determines the outcome of sperm competition in the domestic fowl. Proceedings of the Royal Society of London Series B Biological Sciences 266 1759-1764.

Burness G, Casselman SJ, Schulte-Hostedde AI, Moyes CD \& Montgomerie R 2004 Sperm swimming speed and energetics vary with sperm competition risk in bluegill (Lepomis macrochirus). Behavioral Ecology and Sociobiology 56 65-70.

Ciereszko A \& Dabrowski K 1994 Relationship between biochemical constituents of fish semen and fertility. The effect of short term storage. Fish Physiology and Biochemistry 12 357-367.

Cosson J, Billard R, Cibert C, Dreanno C \& Suquet M 1999 Ionic factors regulating the motility of fish sperm. In From Basic Science the Male Gamete to Clinical Application, pp 161-186. Ed. C Gagnon. Vienna, IL: Cache River Press.

Donnelly ET, Lewis SEM, McNally JA \& Thompson W 1998 In vitro fertilization and pregnancy rates: the influence of sperm motility and morphology on IVF outcome. Fertility and Sterility $\mathbf{7 0}$ 305-314.

Donoghue AM 1999 Prospective approaches to avoid flock fertility problems: predictive assessment of sperm function traits in poultry. Poultry Science 78 437-443.

Gage MJG, Stockley P \& Parker GA 1995 Effects of alternative male mating strategies on characteristics of sperm production in the Atlantic salmon (Salmo salar): theoretical and empirical investigations. Philosophical Transactions of the Royal Society of London Series B Biological Sciences $350391-399$.

Gage MJG, MacFarlane C, Yeates S, Shackleton R \& Parker GA 2002 Relationships between sperm morphometry and sperm motility in the Atlantic salmon. Journal of Fish Biology 61 1528-1539.

Gage MJG, MacFarlane CP \& Yeates S 2004 Spermatozoal traits and sperm competition in Atlantic salmon: Relative sperm velocity is the primary determinant of fertilization success. Current Biology 14 44-47.

Gile SR \& Ferguson MM 1995 Factors affecting male potency in pooled gamete crosses of rainbow-trout, Oncorhynchus mykiss. Environmental Biology of Fishes 42 267-275. 
Katasonov VYa 1973 Investigation of color in hybrids of common and ornamental (Japanese) carp. Communication I. Transmission of dominant color types. Soviet Genetics (Genetika) 9 985-992.

Katasonov VYa 1978 Color in hybrids of common and ornamental (Japanese) carp III. Inheritance of blue and orange color types. Soviet Genetics (Genetika) 14 1522-1528.

Kirpichnikov VS 1979 In Genetic Bases of Fish Selection, Translated by G.G. Gause, 1981. Berlin: Springer Verlag.

Kortet R, Vainikka A, Rantala MJ \& Taskinen J 2004 Sperm quality, secondary sexual characters and parasitism in roach (Rutilus rutilus L.). Biological Journal of the Linnean Society 81 111-117.

Lahnsteiner F, Berger B, Weismann T \& Patzner RA 1998 Determination of semen quality of the rainbow trout, Oncorhynchus mykiss, by sperm motility, seminal plasma parameters, and spermatozoal metabolism. Aquaculture 163 163-181.

Levitan DR 2000 Sperm velocity and longevity trade off each other and influence fertilization in the sea urchin Lytechinus variegates. Proceedings of the Royal Society of London Series B Biological Sciences $267531-534$

Liley NR, Tamkee P, Tsai R \& Hoysak DJ 2002 Fertilization dynamics in rainbow trout (Oncorhynchus mykiss): effect of male age, social experience, and sperm concentration and motility on in vitro fertilization. Canadian Journal of Fisheries and Aquatic Sciences 59 144-152.

Linhart O, Cosson J, Mims SD, Shelton WL \& Rodina M 2002 Effects of ions on the motility of fresh and demembranated paddlefish (Polyodon spathula) spermatozoa. Reproduction 124 713-719.

Linhart O, Rodina M, Gela D, Kocour M \& Rodriguez M 2003 Improvement of common carp artificial reproduction using enzyme for elimination of eggs stickiness. Aquatic Living Resources 16 450-456.

Martin PA, Reimers TJ, Lodge JR \& Dzuik PJ 1974 The effect of ratios and numbers of spermatozoa mixed from two males on proportions of offspring. Journal of Reproduction and Fertility 39 251-258.

Mendel G 1865 Experiment in plant hybridization. In Reprinted in Classic Papers in Genetics, pp 3-22. Ed. JA Peters. Englewood Cliffs, NJ: Prentice Hall.

Moccia RD \& Munkittrick KR 1987 Relationship between the fertilization of rainbow trout (Salmo gairdneri) eggs and the motility of spermatozoa. Theriogenology 27 679-688.

Parker GA 1982 Why are there so many tiny sperm? Sperm competition and the maintenance of two sexes. Journal of Theoretical Biology 96 281-294.
Parker GA 1998 Sperm competition and evolution of ejaculates: towards a tudory base. In Sperm Competition and Sexual Selection, pp 3-54. Eds TR Birkhead \& AP Møller. London: Academic Press.

Parker GA, Ball MA, Stockley P \& Gage MJG 1996 Sperm competition games: Individual assessment of sperm competition intensity by group spawners. Proceedings of the Royal Society of London Series B Biological Sciences 263 1291-1297.

Petersen CW \& Warner RR 1998 Sperm competition in fishes. In Sperm Competition and Sexual Selection, pp 435-464. Eds TR Birkhead \& AP Møller. London: Academic Press.

Reichard M, Jurajda P \& Smith C 2004a Male-male interference competition decreases spawning rate in the European bitterling (Rhodeus sericeus). Behavioral Ecology and Sociobiology $\mathbf{5 6}$ $34-41$.

Reichard M, Smith C \& Jordan WC $2004 b$ Genetic evidence reveals density-dependent mediated success of alternative mating behaviours in the European bitterling (Rhodeus sericeus). Molecular Ecology 13 1569-1578.

Rothbard S, Rubinsthein I \& Gelman E 1996 Storage of common carp (Cyprinus carpio L.) eggs for short durations. Aquaculture Research 27 175-181.

Stockley P, Gage MJG, Parker GA \& Møller AP 1997 Sperm competition in fishes: the evolution of testis size and ejaculate characteristics. American Naturalist 149 933-954.

Vladic TV \& Jarvi T 2001 Sperm quality in the alternative reproductive tactics of Atlantic salmon: the importance of the loaded raffle mechanism. Proceedings of the Royal Society of London Series B Biological Sciences 268 2375-2381.

Vladic TV, Afzelius BA \& Bronnikov GE 2002 Sperm quality as reflected through morphology in salmon alternative life histories. Biology of Reproduction 66 98-105.

Wedekind C, Chapuisat M, Macas E \& Rulicke T 1995 Non-random fertilization in mice correlates with $\mathrm{MHC}$ and something else. Heredity 77 331-369.

Zeh JA \& Zeh DW 1997 The evolution of polyandry II: post-copulatory defences against genetic incompatibility. Proceedings of the Royal Society of London Series B Biological Sciences 264 $69-75$.

Received 8 July 2005

Accepted 26 July 2005 